\title{
Perceptions of Inequality During the Coronavirus Outbreak
}

\author{
Ugur Yildirim \\ University of California, Berkeley
}

July 20, 2020

\begin{abstract}
Corresponding Author: Ugur Yildirim, Sociology Department, University of California, Berkeley, 410 Barrows Hall, Berkeley, CA 94720-1980. Email: ugur.yildirim@berkeley.edu
\end{abstract}

Acknowledgments: The author thanks David Harding, Daniel Schneider, Dennis Feehan, and Gabriel Lenz for all of their helpful comments, Anam Ahmed for kindly taking the time to record the experimental texts used in the study, and UC Berkeley XLab, Don Moore in particular, for the generous research grant that funded this study.

Word count: 7,000 (text, endnotes, references) 


\title{
Perceptions of Inequality During the Coronavirus Outbreak
}

\begin{abstract}
It is known that Americans' preferences for redistribution are generally not very elastic in relation to their perceptions of inequality. Even localized crises such as Hurricane Katrina that lay bare existing inequalities in society seem to do little to nothing in moving public opinion on this matter. However, the coronavirus pandemic presents a new opportunity for social scientists and policy experts to test whether large-scale national crises can lead to changes in people's opinions. What is the impact of a crisis of this proportion on Americans' attitudes towards inequality? More specifically, is there an "added value" to being informed about class inequalities in the context of the coronavirus outbreak compared to being informed about such inequalities in general terms without reference to this extraordinary event? This study answers these questions using an online experiment that manipulates the information respondents receive prior to answering survey questions. I find that receiving information about class inequalities specifically in relation to the outbreak tends to be much more effective in moving people's opinions compared to receiving that information in a way that does not directly relate it to coronavirus. This suggests that attitudes can be moved by something as widespread and salient as the pandemic.
\end{abstract}

Keywords: coronavirus (COVID-19); public opinion; inequality; redistribution; survey experiment 


\section{Perceptions of Inequality During the Coronavirus Outbreak}

\section{Introduction}

Attitudes towards inequality is a key component of Americans' distributional preferences, which have been shown to affect their political and voting behavior (Fisman, Jakiela, and Kariv 2017). We know that Americans generally prefer economic regimes that are at least somewhat unequal (Norton and Ariely 2011, Norton 2014), and that they are not particularly supportive of policies intended to address inequality, at least traditional government redistributive policies (Dallinger 2010, McCall 2013, McCall et al 2017).

Evidence suggests that even large events such as the Hurricane Katrina disaster that struck New Orleans in 2005 and exposed racial and class inequalities in the US (Bobo 2006, Belkhir and Charlemaine 2007) might not be enough to change Americans' attitudes towards inequality and redistribution. For example, Grusky and Ryo (2006) found that Hurricane Katrina did not have much of an impact on raising awareness and activism in relation to inequality and poverty in the US. Similarly, Sweeney (2006) found that even after Hurricane Katrina, most Americans remained "color-blind" towards inequality.

Part of the reason why Americans' views about inequality are generally not very elastic to information is that inequality (un)awareness is rarely the main driver of those views. In particular, it has been shown that low levels of support for redistribution are due not so much to unawareness or indifference as to the failure to connect social issues and public policy (Bartels 2005, Kuziemko et al 2015). Furthermore, given America's entrenched political divide, most Americans end up interpreting the information they receive in a way that aligns with their 
pre-existing views, and so a "liberal" message about inequality is unlikely to change the opinions of conservative Americans (Grusky and Ryo 2006, Sweeney 2006).

Given this background, is there reason to believe that the coronavirus outbreak might have an impact on Americans' views about inequality? The coronavirus pandemic that we are currently in the midst of resembles the natural disasters of the recent past, including Hurricane Katrina in New Orleans and Camp Fire in California, in terms of disproportionately affecting low-income people (Pirtle 2020, Ray and Rojas 2020, Von Braun, Zamagni, and Sorondo 2020). However, the current situation is unique in terms of its scope: as opposed to the localized crises of the past that primarily affected particular sites or states, the current crisis is a truly national, even global, one. This is important because opinions are more likely to move when people are directly affected by a given situation or when the concrete implications of the situation are made clear to the people (Connell et al 2006, Lowe et al 2006), and the coronavirus crisis has had a direct impact on the lives of almost everyone in the country.

What is the impact of a crisis of this proportion on Americans' attitudes towards inequality? More specifically, is there an "added value" to being informed about class inequalities in the context of the coronavirus outbreak compared to being informed about such inequalities in general terms without reference to this extraordinary event? This study answers these questions using an online experiment that manipulates the information respondents receive prior to answering survey questions. I find that receiving information about class inequalities specifically in relation to the outbreak tends to be much more effective in moving people's opinions compared to receiving that information in a way that does not directly relate it to 
coronavirus. This suggests that attitudes can be moved by something as widespread and salient as the pandemic.

The paper is organized as follows. The next section sets up the theoretical background underlying the study and fleshes out the hypotheses being tested. The section after that describes the methodological aspects of the study including experimental design, implementation, subject recruitment, measures, and analytical strategy. The following section presents the main results of the study related to inequality perceptions and redistributive preferences. Finally, the last section discusses the main findings of the study and mentions ideas for future research.

\section{Theoretical background}

Inequality is high and on the rise in many countries around the globe, including the US (Piketty and Saez 2006, McCall and Percheski 2010, Alvaredo et al 2018). One of the most tangible consequences of inequality is health disparities within and between countries (Murray, Kulkarni. and Ezzati 2005, Adler and Rehkopf 2008, Braveman et al 2010, Marmot 2015). Disease outbreaks such as the new coronavirus pandemic that we are currently in the midst of make health inequalities all the more apparent (Quinn and Kumar 2014).

In the US, while governors around the country issued shelter-in-place and stay-at-home orders in an attempt to "flatten the curve" (Thunstrom et al 2020), only some people are lucky enough to be able to follow these orders; others have to go out everyday due to the nature of their work or their financial status (Valentino-DeVries, Lu, and Dance 2020). Relatedly, minorities

such as African Americans and low-income people in general are reported to have higher risks of mortality during the outbreak (Dyer 2020). 
How is this situation affecting Americans' attitudes towards inequality? In particular, does becoming sensitized to class disparities "open people's eyes" to inequality and make them more supportive of redistribution? Or, does inequality awareness lead to a sort of "victim blaming" whereby the disadvantaged groups are blamed for their situation? Preferences for redistribution has been studied extensively in the social science and policy literatures, where scholars have identified numerous factors that could affect these preferences and the demand for more equal incomes.

\section{Perceptions of inequality}

The first set of factors is related to actual and perceived levels of inequality in the country, including whether inequality is rising or not. The median voter hypothesis stipulated that as inequality rises, support for redistribution rises as well (Meltzer and Richard 1981). While Kenworthy and McCall (2008) found little empirical support for this hypothesis, Engelhardt and Wagener (2014), Niehues (2014), Hauser and Norton (2017), and Gimpelson and Triesman (2018) all make the same point -- and support it with empirical evidence -- that what matters when it comes to policy preferences is not actual but perceived inequality.

McCall (2013) too investigates the relationship between perceptions of inequality and support for government action against inequality but finds only weak evidence for this, at least in the US. In a similar vein, Kuziemko et al (2015) finds that while information about inequality has a significant effect on Americans' views on inequality, such information is mostly ineffective in moving policy preferences, with the exception of estate tax. On the other hand, $\underline{\text { McCall et al }}$ 
(2017) finds that exposure to information about rising inequality actually has a significant effect on respondents' support for policies that reduce economic inequality.

\section{Perceptions of opportunity and related concepts}

Parallel to this research that studied the effect of inequality perceptions on preferences, and inspired by some of the evidence that found weak to no inequality effect in this regard, other researchers started instead from the premise that people may care more about something other than economic inequality, such as economic mobility, opportunity, or simply a general sense of fairness (Starmans, Sheskin, and Bloom 2017) -- these constitute the second set of factors to be discussed. In particular, Alesina and Angeletos (2005) proposed a model that claimed that societies where it is believed that individual effort -- as opposed to luck, family, connections, and so on -- determines income tend to favor low redistribution and low taxes.

In line with this model, Alesina and La Ferrara (2005) found that Americans who believe in the existence of equal opportunity are more likely to be against redistribution. Krawczyk (2010) reached a similar conclusion that people are less willing to give to others when the community rules emphasize effort as opposed to luck. Similarly, Bjornskov et al (2013) discovered that there is a negative association between fairness perceptions and demand for equal incomes. Finally, Shariff, Wiwad, and Aknin (2016) found that perceptions of upward mobility $^{1}$ make people more tolerant of inequality, while Alesina, Stantcheva, and Teso (2018) found that receiving pessimistic information about mobility makes respondents more supportive of redistribution. $^{2}$ 


\section{Inequality and government}

The third set of factors relates specifically to Americans' perceptions of government and its role in society. As discussed in Kuziemko et al (2015), and before that in Bartels (2005), one possible reason why Americans might not support government action on inequality is that they fail to make the connection between social issues and public policy. Another reason, also discussed in

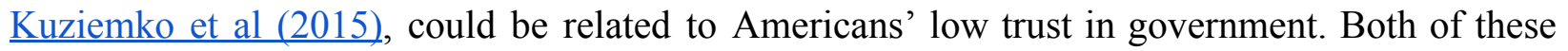
ideas would explain the apparent discrepancy between Americans' concern for inequality and their unwillingness to do much about it (Bartels 2005, McCall 2013).

\section{Socio-demographic factors}

Beyond the three sets of core factors just discussed, many socio-demographic factors have also been claimed to influence preferences for redistribution. In particular, researchers have shown that high income is associated with less support for redistribution, while low income is associated with more support (Corneo and Gruner (2002), Alesina and La Ferrara 2005, Steele 2015). As discussed in Corneo and Gruner (2002), such a negative association between income and support for redistribution can be explained in reference to self-interest -- they call this the "homo oeconomicus effect."

In addition to income, political orientation has also been shown to influence redistributive preferences. The literature is in agreement that conservative people and Republicans are much less likely to support redistribution (Chambers, Swan, and Heesacker 2015, Reynolds and Xian 2014, Alesina, Stantcheva, and Teso 2018). Furthermore, as the debate on whether Americans over- or under-estimate mobility show (Chambers, Swan, and Heesacker 2015, Davidai and 
Gilovich 2015, Kraus and Tan 2015, Swan et al 2017), perceptions of mobility in the country are divided along political lines -- with conservatives being much more optimistic about the state of mobility -- which means that the effects of political orientation and mobility perceptions on redistribution are very much connected.

Finally, while income and political orientation emerge as the key socio-demographic predictors of redistributive preferences, other factors have also been found to be correlated with this outcome. For example, educated people are generally less supportive of redistribution, and females and minorities seem to be more supportive (Corneo and Gruner (2002), Alesina and La Ferrara 2005, Steele 2015).

\section{Hypotheses}

The fact that the coronavirus outbreak made existing inequalities in society all the more apparent provides social scientists with a unique opportunity to understand how awareness of these inequalities shapes Americans' attitudes towards such inequalities and preferences towards doing something about them. Based on earlier findings related to perceptions of inequality discussed above, it is reasonable to predict that:

Hypothesis $1 a$-Awareness of existing class inequalities in society will make Americans more concerned about inequality and more sympathetic to the situation of the disadvantaged.

On the other hand, while a positive outcome such as this is expected based on the literature, it is still possible that awareness of inequality will have the opposite effect through a 
mechanism such as victim blaming whereby the weak is blamed for their unfortunate situation (Martin 2001, Greenbaum 2015):

Hypothesis $1 b$-Awareness of existing class inequalities in society will make Americans less concerned about inequality and less sympathetic to the situation of the disadvantaged.

Regardless of which way the effect moves people's attitudes towards inequality, based on the important point from the literature that concern does not necessarily equal willingness to take action (Bartels 2005, McCall 2013), it is crucial to have separate hypotheses for preferences towards redistribution and reducing inequalities:

Hypothesis $2 a$-Awareness of existing class inequalities in society will make Americans more supportive of redistribution and reducing inequalities.

Hypothesis $2 b$-Awareness of existing class inequalities in society will make Americans less supportive of redistribution and reducing inequalities.

Once again, while the former hypothesis $(2 a)$ is more plausible based on the literature, the latter one $(2 b)$ is nevertheless listed to be explicit about the possibility of the victim blaming mechanism mentioned above. Finally, information about inequality specifically in relation to the coronavirus outbreak -- a potential "rupturing event" -- may lead to a sense of urgency on the side of the receiver (Hedge and Yousif 1992), which could in turn strengthen or amplify the 
effect of inequality on the outcome. Similar to the previous two sets of hypotheses, we can write down two separate hypotheses to remain agnostic to the possible direction of the effect. The following hypotheses argue that coronavirus will amplify effects related to concern for inequality:

Hypothesis $3 a$-Awareness of existing class inequalities directly in relation to the outbreak will make Americans even more concerned about inequality and even more sympathetic to the situation of the disadvantaged compared to awareness of these inequalities in general terms.

Hypothesis $3 b$-Awareness of existing class inequalities directly in relation to the outbreak will make Americans even less concerned about inequality and even less sympathetic to the situation of the disadvantaged compared to awareness of these inequalities in general terms.

And, the last set of hypotheses argue that coronavirus will amplify effects related to support for redistribution and reducing inequalities:

Hypothesis $4 a$-Awareness of existing class inequalities directly in relation to the outbreak will make Americans even more supportive of redistribution and reducing inequalities compared to awareness of these inequalities in general terms. 
Hypothesis $4 b$-Awareness of existing class inequalities directly in relation to the outbreak will make Americans even less supportive of redistribution and reducing inequalities compared to awareness of these inequalities in general terms.

\section{Methods}

\section{Experimental design}

The study is designed as a between-subjects survey experiment. Given that (i) any discussion of the outbreak may or may not touch upon inequality, and (ii) any discussion of inequality may or may not relate to the outbreak directly, the experiment randomized each respondent into one of six conditions -- three of them having coronavirus-specific primes and the other three having general primes (Table 1).

The three coronavirus conditions correspond to the three possible framings of the pandemic: (1) the "equal pandemic" that is affecting all of us (coronavirus control); (2) the unequal pandemic that is especially hard on poor and low-income communities, minorities in particular ("coronavirus class inequality"); and (3) the unequal pandemic that is especially hard on the elderly and those with medical conditions ("coronavirus natural inequality"). Directly parallel to these are the three general conditions: (4) a brief history of the internet (control); (5) class inequality without any reference to coronavirus; and (6) natural inequality without any reference to coronavirus. ${ }^{3}$

Table 1 About Here 
The experiment flows as follows. First, respondents are recruited into the study and asked to give their consent. (At this stage, respondents are told that the goal of the survey is to "understand the public's opinions regarding important societal and economic trends in the US." This general wording is chosen over using specific words such as coronavirus and inequality in an attempt to make sure respondents are not primed to think about these issues from the start.) Second, they are asked to watch a short clip with subtitles and told that the purpose of showing this video is to assess their comprehension skills; the content of the clips depends on the experimental condition respondents are in.

Third, right after watching the video, they are asked to briefly describe the content of the video using their own words. Fourth, they answer a series of questions related to their attitudes towards inequality, opportunity, deservingness, and redistribution. Fifth, the respondents answer a series of demographic questions, including their income and political orientation. Finally, respondents answer questions that are specifically related to the coronavirus outbreak. ${ }^{4}$

\section{Implementation and subject recruitment}

The survey experiment is implemented using Qualtrics. The videos presented to respondents as part of the experiment are prepared using iMovie and subsequently uploaded to a YouTube channel created by the researcher (videos are "unlisted", have comments disabled, and show subtitles by default). All videos showed an Adobe Stock licensed image in the background related to the content of the narrated text. The experimental texts themselves are written by the researcher after a careful reading of relevant news articles and scientific communications. 
The texts narrated to respondents in the videos are recorded by a young female in her 20's speaking Standard American English. Female voice is chosen over male voice due to evidence that shows that people tend to find the female voice to be more credible (Siegel, Breazeal, and Norton 2009). The narrated text is also displayed as actual text under the video in case the respondent experiences a problem watching the video or chooses not to watch. (As discussed later under Results, the researcher confirmed that most respondents watched and understood the videos.)

Data collection took place on Lucid Theorem. This platform gives researchers access to cheap, fast (thousands of responses within hours), and high quality data that is also nationally representative based on age, gender, ethnicity, and region. A recent scholarly work validated the quality of Lucid samples (Coppock and McClellan 2019). The experiment is run on a total of 5,249 Lucid respondents with approximately 875 respondents in each condition. The conditions appear to be balanced on the socio-demographic covariates, which gives us confidence that randomization worked as expected..$^{5}$ All analyses are conducted on a dataset with the following simple structure: one row per respondent and as many columns as there are variables. Respondents are required to be US residents and 18 or older. The project has IRB approval. (All code, materials, and de-identified data will be made public once the study is over.)

\section{Measures}

The study has a large number of outcomes that capture respondents' opinions regarding inequality, redistribution, and related concepts including opportunity, determinants of success, and deservingness. Outcomes related to attitudes towards inequality are (i) whether the 
respondent thinks income inequality is a serious problem; (ii) whether the respondent thinks poverty is a serious problem; and (iii) whether the respondent thinks unequal access to healthcare is a serious problem. All three of these outcomes are measured on a scale of 1 to 5 with higher values denoting more seriousness.

The study also has outcomes that capture respondents' preferences towards redistribution. One set of outcomes asks respondents to report how effective they think certain tools are to address inequality. The relevant outcomes here are (iv) whether the respondent thinks government regulation is effective; (v) whether the respondent thinks government transfers are effective; (vi) whether the respondent thinks progressive taxes are effective; (vii) whether the respondent thinks education policies are effective; and (viii) whether the respondent thinks private charity is effective. All three of these outcomes are measured on a scale of 1 to 5 with higher values denoting more effectiveness.

Respondents are also asked (ix) whether they think the government should reduce inequalities; (x) whether they think major companies should reduce inequalities; and (xi) who they think has the greatest responsibility in reducing inequalities. The first two outcomes are measured on a scale of 1 to 7 with higher values denoting more support for reducing income and pay differences. The third variable is a forced choice question, which allows us to create separate binary variables for: income differences do not need to be reduced; low income individuals themselves; high income individuals themselves; private charity; major companies; and government.

In addition to these outcomes directly related inequality and redistribution, the survey has several outcomes that help us capture respondents' opinions towards related concepts. The 
opportunity outcomes are (xii) whether the respondent thinks Americans today have enough opportunities (on a scale of 1-3) and (xiii) whether they think Americans today have more or less opportunities compared to their parents (on a scale of 1-3). The main outcomes related to determinants of success are (xiv) whether the respondent thinks hard work or luck is more important for success (on a scale of 1-7) and (xv) whether they think people are poor because of laziness or because of an unfair society (on a scale of 1-7). The study also has two deservingness outcomes, which are (xvi) whether the respondent thinks high earners deserve their income incomes (on a scale of 1-5) and (xvii) whether they think low earners deserve their low incomes (on a scale of 1-5).

The main predictor in the study is the informational treatment. It can be thought of as a single variable with six levels, or it can be viewed as the combination of two separate variables, namely (1) whether the treatment relates to coronavirus or not, and (2) whether the treatment provides any information about natural or class inequalities. In addition to the main predictor, the survey includes a large number of socio-demographic covariates, including household income, political orientation, level of education, gender, and race, among others.

\section{Analytical strategy}

The main statistical model fit to data is a linear regression of the outcome on the experimental condition treated as a categorical variable with six levels. The general control condition is used as the reference category to be able to get estimates for coronavirus and inequality conditions. In other words, this model allows us to separately estimate effects associated with each of the five 
non-control conditions. Estimates presented in Tables 3 and 4 are based on this model. The general form of the model is described in Equation 1.

$$
y=\beta_{0}+\beta_{1} \text { cor_control }+\beta_{2} \text { class }+\beta_{3} \text { cor_class }+\beta_{4} \text { natural }+\beta_{5} \text { cor_natural }+\varepsilon
$$

In addition to this main model, separate models are fit when appropriate to estimate effects associated with (i) receiving any kind of coronavirus information, that is, all three coronavirus conditions viewed as a whole, and (ii) receiving any kind of information about inequalities, that is, the two class inequality conditions and the two natural inequality conditions viewed as wholes. Estimates presented in Table 2 are based on these models. The general form of the models are described in Equations 2 and 3, respectively.

$$
\begin{gathered}
y=\gamma_{0}+\gamma_{1} \text { coronavirus }+\varepsilon \quad \text { (2) } \\
y=\delta_{0}+\delta_{1} \text { class_ineq }+\delta_{2} \text { natural_ineq }+\varepsilon
\end{gathered}
$$

In the case of all three of these models, results both with and without socio-demographic covariates are presented for the sake of transparency (Lenz and Sahn 2020). In general, given that the independent variable is randomly assigned to respondents, the two results are very similar.

\section{Results}




\section{Does the informational treatment sensitize people to inequality?}

Results show that respondents who received one of the coronavirus treatments were significantly less likely to say that high earners deserve their high incomes (coefficient estimate $=-0.077$, $\mathrm{p}$-value $=0.002)($ Table 2 , high deserve $)$. On the other hand, no significant treatment effects were observed with the outcome related to whether low earners deserve their low incomes (coefficient estimate $=-0.022, \mathrm{p}$-value $=0.425)$ (Table 2 , low deserve). While the effect sizes are substantially small, these results suggest that the coronavirus treatments could have slightly increased sensitivity towards inequality among respondents.

The class axis was also influential in moving people's opinions towards inequality. In particular, receiving one of the two class treatments made respondents significantly less likely to say that income differences do not need to be reduced (coefficient estimate $=-0.0341$, p-value $<$ 0.001) (Table 2, don't reduce). Once again, the substantive effect here is small (around 3-4\%). While the class treatments were able to slightly move attitudes towards income differences, no significant effects are observed regarding support for government or major companies actually reducing these income differences. In this case, the coefficient estimates are 0.018 (p-value $=$ 0.792) for support for government reducing income differences (Table 2, govt reduce) and 0.071 $(p$-value $=0.258)$ for major companies reducing pay differences (Table 2, comps reduce). These results suggest that while the class treatments were able to make people slightly more concerned about inequality, they might not have been strong enough to move people's opinions towards redistribution. 
Table 2 About Here

Overall, based on the results presented in this subsection, we have some evidence to support Hypothesis 1 a over Hypothesis $1 b$. On the other hand, the evidence is not strong enough to support either Hypothesis $2 a$ or Hypothesis $2 b$, but the former one seems more likely given the direction in which the treatments moved preferences for reducing inequalities.

\section{Does coronavirus amplify class effects?}

Digging deeper into effects associated with each specific experimental condition showed that in most instances the general class treatment was not strong enough to move respondents' opinions, while the coronavirus class treatment led to significant shifts in opinion. First of all, as far as opportunity perceptions are concerned, the general class treatment failed to move either of the two opportunity outcomes. The coefficient estimates here are -0.004 ( $\mathrm{p}$-value $=0.887$ ) for the enough opportunities question and $-0.012(p$-value $=0.747)$ for the opportunities compared to the parents question. On the other hand, in both of these instances, the coronavirus class inequality conditions led to larger shifts in opinion, making respondents' opportunity perceptions more pessimistic. The corresponding coefficient estimates are -0.060 (p-value $=0.052)$ and $(-0.089$, p-value $=0.024)($ Table 3 , enough opps, better opps $)$.

Similarly, the coronavirus class inequality condition moved respondents' inequality perceptions towards thinking that inequality is a serious problem, while the general class inequality condition was generally not strong enough. In particular, the coefficient estimates for inequality being a serious problem, poverty being a serious problem, and unequal access to 
healthcare being a serious problem are $0.155(\mathrm{p}$-value $=0.006), 0.127(\mathrm{p}$-value $=0.012)$, and $0.164(p$-value $=0.003)$ for coronavirus class inequality, while the estimates are $0.136(p$-value $=$ $0.016), 0.069(\mathrm{p}$-value $=0.169)$, and $0.073(\mathrm{p}$-value $=0.185)$ for general class inequality. It is also important to note here that even the coronavirus control condition, which doesn't explicitly refer to inequality in any way, was able to significantly move respondents' inequality perceptions, with the corresponding coefficient estimates being 0.149 ( $\mathrm{p}$-value $=0.008), 0.119$ $(\mathrm{p}$-value $=0.018)$, and $0.134(\mathrm{p}$-value $=0.016)($ Table 3, ineq problem, povty problem, hcare problem). These results suggest that coronavirus, with or without a direct reference to inequality, made respondents more conscious of inequality.

Table 3 About Here

As far as opinions regarding concrete government tools to address inequality are concerned, results show that receiving information about class inequality in the context of the outbreak made respondents more likely to say that government transfers are effective (coefficient estimate $=0.209, \mathrm{p}$-value $<0.001)$. There is also some indication of a similar effect for government regulation being effective (coefficient estimate $=0.100, \mathrm{p}$-value $=0.081$, while no significant effects were observed for progressive taxes being effective $(0.075$, p-value $=0.183)$. The general class inequality condition is not significant in either of these cases, with coefficient estimates being $0.066(p$-value $=0.247), 0.088(p$-value $=0.125)$, and $0.011(p$-value $=0.843)$, respectively (Table 4, transfers eff, regulation eff, prog taxes eff). 
On the other hand, both class inequality conditions lead to significant increases in thinking that education policies and private charity are effective tools. In fact, the general class inequality condition actually has stronger effects in these areas with coefficient estimates being $0.124(\mathrm{p}$-value $=0.018)$ and $0.132(\mathrm{p}$-value $=0.014)$ for general class inequality and 0.103 $(\mathrm{p}$-value $=0.051)$ and $0.093(0.086)$ for coronavirus class inequality (Table 4 , educ pols eff, priv charity eff).

Table 4 About Here

Results presented in this subsection support Hypothesis $3 a$. Furthermore, if we interpret opinions regarding how effective certain tools are in addressing inequality to reflect preferences for redistribution, Hypothesis $4 a$ is supported as well. That said, the latter statement should be interpreted with caution since, as the previous subsection showed, the treatments were generally not strong enough to move preferences for reducing inequalities.

\section{Discussion}

It is known that Americans' preferences for redistribution are generally not very elastic in

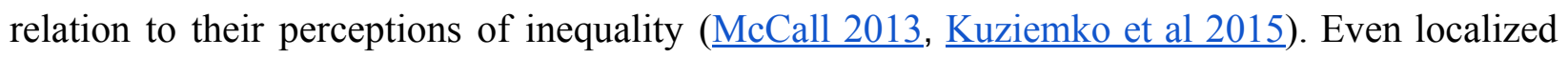
crises such as Hurricane Katrina that lay bare existing inequalities in society seem to do little to nothing in moving public opinion on this matter (Grusky and Ryo 2006, Sweeney 2006). However, the coronavirus pandemic presents a new opportunity for social scientists and policy experts to test whether large-scale national crises can lead to changes in people's opinions. What 
is the effect of discussing inequality in the context of coronavirus on Americans' attitudes towards inequality and redistribution?

The most interesting pattern observed in the results presented above is that being informed about class inequalities in the context of the coronavirus outbreak tends to be much more effective in moving people's opinions compared to being informed about such inequalities in general terms without reference to this extraordinary event. For example, while general information about inequality has no statistically detectable effect on whether respondents think unequal access to healthcare is a problem or not, information that explicitly connects inequality to coronavirus makes respondents significantly more likely to think that unequal access to healthcare is a serious problem.

Similarly, only when inequality is discussed in conjunction with the outbreak were the informational treatment strong enough to move respondents' opinions regarding whether government transfers are an effective tool to address inequality. On the other hand, no matter how the inequality information is presented -- with or without any reference to coronavirus -- the experiment did not have any detectable effects on concrete opinions as to whether the government, or major companies, should actually reduce income differences or not. This is perhaps not surprising given how entrenched Americans' redistributive preferences are.

Together, these findings suggest that the debate revolving around the coronavirus outbreak, especially when connections to inequality were made explicit, could increase concern about inequality among the public, and perhaps even shift opinions regarding specific government tools to address inequality -- government transfers in particular -- even if opinions regarding reducing inequalities remain entrenched. All of this implies that crisis times such as 
this one could present fruitful opportunities for politicians and opinion leaders to reframe the inequality debate in the country and get the message across to more Americans that inequality is a problem.

This study helps answer important questions about the impact of the coronavirus outbreak on the public's attitudes towards inequality, but it also raises new ones. In particular, it is unclear which of the effects observed in this study will persist over time. For example, it could simply be that the observed effect on preferences towards government transfers is special to the given situation when many people have been directly affected by the coronavirus stimulus checks. Will the coronavirus outbreak lead to a long-term increase in the belief that government transfers are effective? Even more fundamentally, will Americans maintain a higher level of concern for inequality once the coronavirus situation goes back to normal, or will everyone simply revert back to their old opinions? The answers to these questions will no doubt depend on how opinion leaders end up framing the debate.

\section{Endnotes}

1 See Benabou and Ok (2001) and Cojocaru (2014) for more information on the influential "prospect of upward mobility" (POUM) hypothesis.

2 Beyond perceptions of mobility, the actual mobility experience might also influence preferences for redistribution through mechanisms such as upward mobility making an individual more effort-oriented and more likely to subscribe to the idea that income and position need to be earned, not handed out by others (Piketty 1995). Note that while there are several empirical findings related to mobility effects in the literature (Alesina and La Ferrara 2005, Corneo and Gruner 2002, Clark and D'Angelo 2009, Siedler and Sonnenberg 2012, Steele 2015, Gugushvili 2018, Jaime-Castillo and Marques-Perales 2019), the identification problem inherent to estimating 
origin-destination-mobility effects, which is practically identical to the age-period-cohort identification problem, makes this exercise very tricky (Fosse and Pfeffer 2019, Fosse and Winship 2019a, Fosse and Winship 2019b).

3 The two natural inequality conditions are included here for the sake of completeness since they were part of the experiment that was run; however, results pertaining to them are not directly relevant to the main focus of this paper.

4 See Appendix A for the experimental texts, images, videos, manipulation check question, survey questions, and other related project content.

5 See Appendix B for information on sample size calculations, exact sample sizes by condition, and summary socio-demographics by condition.

\section{References}

Adler, Nancy E. and David H. Rehkopf. 2008. "U.S. Disparities in Health: Descriptions, Causes, and Mechanisms." Annual Review of Public Health 29: 235-252.

Alesina, Alberto and George-Marios Angeletos. 2005. "Fairness and Redistribution." The American Economic Review 95(4): 960-980.

Alesina, Alberto and Eliana La Ferrara. 2005. "Preferences for redistribution in the land of opportunities." Journal of Public Economics 89: 897-931.

Alesina, Alberto, Stefanie Stantcheva, and Edoardo Teso. 2018. "Intergenerational Mobility and Preferences for Redistribution." American Economic Review 108(2): 521-554.

Alvaredo, Facundo, Lucas Chancel, Thomas Piketty, Emmanuel Saez, and Gabriel Zucman. 2018. "The Elephant Curve of Global Inequality and Growth." AEA Papers and Proceedings 108: 103-108.

Bartels, Larry M. 2005. "Homer Gets a Tax Cut: Inequality and Public Policy in the American Mind." Perspectives on Politics 3(1): 15-31. 
Belkhir, Jean Ait and Christiane Charlemaine. 2007. "Race, Gender and Class Lessons from Hurricane Katrina." Race, Gender \& Class 14(1/2): 120-152.

Benabou, Roland and Efe A. Ok. 2001. "Social Mobility and the Demand for Redistribution: the POUM Hypothesis." Quarterly Journal of Economics 116(2): 447-487.

Bjornskov, Christian, Axel Dreher, Justina A.V. Fischer, Jan Schnellenbach, and Kai Gehring. 2013. "Inequality and Happiness: When Perceived Social Mobility and Economic Reality Do Not Match.” Journal of Economic Behavior and Organization 91: 75-92.

Bobo, Lawrence D. 2006. "Katrina: Unmasking Race, Poverty, and Politics in the $21^{\text {st }}$ Century." Du Bois Review: Social Science Research on Race 3(1): 1-6.

Braveman, Paula A., Catherine Cubbin, Susan Egerter, David R. Williams, and Elsie Pamuk. 2010. "Socioeconomic Disparities in Health in the United States: What the Patterns Tell Us." American Journal of Public Health 100(S1): 1375-1378.

Chambers, John R., Lawton K. Swan, and Martin Heesacker. 2015. "Perceptions of U.S. Social Mobility Are Divided (and Distorted) Along Ideological Lines." Psychological Science 26(4): 413-423.

Clark, Andrew E. and Emanuela D’Angelo. 2009. “Upward Social Mobility, Well-being and Political Preferences: Evidence from the BHPS." Working Papers 338, Università Politecnica delle Marche (I), Dipartimento di Scienze Economiche e Sociali.

Cojocaru, Alexandru. 2014. "Prospects of upward mobility and preferences for redistribution: Evidence from the Life in Transition Survey." European Journal of Political Economy 34: 300-314. 
Connell, Sharon, John Fien, Jenny Lee, Helen Sykes, and David Yenchen. 2006. “'If It Doesn't Directly Affect You, You Don't Think About It': a qualitative study of young people's environmental attitudes in two Australian cities." Environmental Education Research 5(1): 95-113.

Coppock, Alexander and Oliver A. McClellan. 2019. "Validating the demographic, political, psychological, and experimental results obtained from a new source of online survey respondents." Research and Politics January-March: 1-14.

Corneo, Giacomo and Hans Peter Gruner. 2002. "Individual preferences for political redistribution." Journal of Public Economics 83(1): 83-107.

Dallinger, Ursula. 2010. "Public support for redistribution: what explains cross-national differences?" Journal of European Social Policy 20(4): 333-349.

Davidai, Shai and Thomas Gilovich. 2015. "Building a More Mobile America—One Income Quintile at a Time." Perspectives on Psychological Science 10(1): 60-71.

Dyer, Owen. 2020. "Covid-19: Black people and other minorities are hardest hit in US." BMJ 369: $\mathrm{m} 1483$.

Engelhardt, Carina and Andreas Wagener. 2014. "Biased Perceptions of Income Inequality and Redistribution." CESifo Working Paper Series No. 4838.

Fisman, Raymond, Pamela Jakiela, and Shachar Kariv. 2017. "Distributional preferences and political behavior." Journal of Public Economics 155: 1-10.

Fosse, Ethan and Fabian T. Pfeffer. 2019. "Beyond the Diagonal Reference Model: Critiques and New Directions." PAA. 
Fosse, Ethan and Christopher Winship. 2019a. “Analyzing Age-Period-Cohort Data: A Review and Critique." Annual Review of Sociology 45: 467-492.

Fosse, Ethan and Christopher Winship. 2019b. "Bounding Analyses of Age-Period-Cohort Effects." Demography 56: 1975-2004.

Gimpelson, Vladimir and Daniel Treisman. 2018. "Misperceiving Inequality." Economics \& Politics 30: 27-54.

Greenbaum, Susan D. 2015. Blaming the Poor: The Long Shadow of the Moynihan Report on Cruel Images about Poverty. New Jersey: Rutgers University Press.

Grusky, David B. and Emily Ryo. 2006. "Did Katrina Recalibrate Attitudes Toward Poverty And Inequality? A Test of the 'Dirty Little Secret' Hypothesis.” Du Bois Review: Social Science Research on Race 3(1): 59-82.

Gugushvili, Alexi. 2018. "A multilevel analysis of perceived intergenerational mobility and welfare state preferences." Int J Soc Welfare 28: 16-30.

Hauser, Oliver P. and Michael I. Norton. 2017. "(Mis)perceptions of inequality." Current Opinion in Psychology 18: 21-25.

Hedge, Alan and Yousif H. Yousif. 1992. "Effects of Urban Size, Urgency, and Cost on Helpfulness: A Cross-Cultural Comparison between the United Kingdom and the Sudan.” Journal of Cross-Cultural Psychology 23(1): 107-115.

Jaime-Castillo, Antonio M. and Ildefonso Marques-Perales. 2019. "Social mobility and demand for redistribution in Europe: a comparative analysis." The British Journal of Sociology 70(1): 138-165. 
Kenworthy, Lane and Leslie McCall. 2008. "Inequality, public opinion and redistribution." Socio-Economic Review 6(1): 35-68.

Kraus, Michael W. and Jacinth J.X. Tan. 2015. "Americans overestimate social class mobility." Journal of Experimental Social Psychology 58: 101-111.

Krawczyk, Michal. 2010. "A glimpse through the veil of ignorance: Equality of opportunity and support for redistribution.” Journal of Public Economics 94: 131-141.

Kuziemko, Ilyana, Michael I. Norton, Emmanuel Saez, and Stefanie Stantcheva. 2015. "How Elastic Are Preferences for Redistribution? Evidence from Randomized Survey Experiments." American Economic Review 105(4): 1478-1508.

Lenz, Gabriel and Alexander Sahn. 2020. "Achieving Statistical Significance with Control Variables and without Transparency." Working Paper.

Lowe, Thomas, Katrina Brown, Suraje Dessai, Miguel de Franca Doria, Kat Haynes, and Katharine Vincent. 2006. "Does tomorrow ever come? Disaster narrative and public perceptions of climate change." Public Understanding of Science 15: 435-457.

Marmot, Michael. 2015. "The health gap: the challenge of an unequal world." The Lancet 386(10011): 2442-2444.

Martin, Mike W. 2001. "Responsibility for Health and Blaming Victims." Journal of Medical Humanities 22: 95-114.

McCall, Leslie. 2013. The Undeserving Rich: American Beliefs about Inequality, Opportunity, and Redistribution. New York: Cambridge University Press.

McCall, Leslie and Christine Percheski. 2010. "Income Inequality: New Trends and Research Directions." Annual Review of Sociology 36: 329-347. 
McCall, Leslie, Derek Burk, Marie Laperriere, and Jennifer A. Richeson. 2017. "Exposure to rising inequality shapes Americans' opportunity beliefs and policy support." PNAS 114(36): 9593-9598.

Meltzer, Allan H. and Scott F. Richard. 1981. "A Rational Theory of the Size of Government." Journal of Political Economy 89(5): 914-927.

Murray, Christopher J.L., Sandeep Kulkarni, and Majid Ezzati. 2005. "Eight Americas: New Perspectives on U.S. Health Disparities." American Journal of Preventive Medicine 29(5S1): 4-10.

Niehues, Judith. 2014. "Subjective Perceptions of Inequality and Redistributive Preferences: An International Comparison.” IW-Trends No. 2.

Norton, Michael I. 2014. "Unequality: Who Gets What and Why It Matters." Policy Insights from the Behavioral and Brain Sciences 1(1): 151-155.

Norton, Michael I. and Dan Ariely. 2011. "Building a Better America-One Wealth Quintile at a Time." Perspectives on Psychological Science 6(1): 9-12.

Piketty, Thomas. 1995. "Social Mobility and Redistributive Politics." The Quarterly Journal of Economics 110(3): 551-584.

Piketty, Thomas and Emmanuel Saez. 2006. "The Evolution of Top Incomes: A Historical and International Perspective." AEA Papers and Proceedings 96(2): 200-205.

Pirtle, Whitney N. Laster. 2020. "Racial Capitalism: A Fundamental Cause of Novel Coronavirus (COVID-19) Pandemic Inequities in the United States.” Health Education \& Behavior: 1-5. 
Quinn, Sandra Crouse and Supriya Kumar. 2014. "Health Inequalities and Infectious Disease Epidemics: A Challenge for Global Health Security.” Biosecurity and Bioterrorism: Biodefense Strategy, Practice, and Science 12(5): 263-273.

Ray, Rashawn and Fabio Rojas. 2020. "Inequality during the coronavirus pandemic." Contexts. Accessed July 2, 2020.

Reynolds, Jeremy and He Xian. 2014. "Perceptions of meritocracy in the land of opportunity." Research in Social Stratification and Mobility 36: 121-137.

Shariff, Azim, Dylan Wiwad, and Lara Aknin. 2016. "Income Mobility Breeds Tolerance for Income Inequality: Cross-National and Experimental Evidence." Perspectives on Psychological Science 11(3): 373-380.

Siedler, Thomas and Bettina Sonnenberg. 2012. "Intergenerational Earnings Mobility and Preferences for Redistribution.” IZA Discussion Paper Series No. 6981.

Siegel, Mikey, Cynthia Breazeal, and Michael I. Norton. 2009. "Persuasive Robotics: The influence of robot gender on human behavior." IEEE/RSJ International Conference on Intelligent Robots and Systems October 11-15: 2563-2568.

Starmans, Christina, Mark Sheskin, and Paul Bloom. 2017. "Why people prefer unequal societies.” Nature Human Behaviour 1: 0082.

Steele, Liza G. 2015. "Income Inequality, Equal Opportunity, and Attitudes About Redistribution.” Social Science Quarterly 96(2): 444-464.

Swan, Lawton K., John R. Chambers, Martin Heesacker, and Sondre S. Nero. 2017. "How should we measure Americans' perceptions of socio-economic mobility?" Judgment and Decision Making 12(5): 507-515. 
Sweeney, Kathryn A. 2006. "The Blame Game: Racialized Responses to Hurricane Katrina." Du Bois Review: Social Science Research on Race 3(1): 161-174.

Thunstrom, Linda, Stephen Newbold, David Finnoff, Madison Ashworth, and Jason F. Shogren. 2020. "The Benefits and Costs of Using Social Distancing to Flatten the Curve for COVID-19." Journal of Benefit-Cost Analysis: 1-17.

Valentino-DeVries, Jennifer, Denise Lu, and Gabriel J.X. Dance. 2020. "Location Data Says It All: Staying at Home During Coronavirus Is a Luxury." The New York Times. Accessed June 6, 2020.

Von Braun, Joachim, Stefano Zamagni, and Marcelo Sanchez Sorondo. 2020. "The moment to see the poor." Science 368(6488): 214. 


\section{Tables}

Table 1. Experimental conditions.

\begin{tabular}{|l|l|l|}
\hline & General information & Coronavirus information \\
\hline No information about inequality & Control & Coronavirus control \\
\hline Information about class inequality & Class inequality & Coronavirus class inequality \\
\hline Information about natural inequality & Natural inequality & Coronavirus natural inequality \\
\hline
\end{tabular}


Table 2. Does the informational treatment sensitize people to inequality?

Models w/o any socio-demographic covariates

\begin{tabular}{|l|l|l|l|l|l|}
\hline & high deserve & low deserve & don't reduce & govt reduce & comps reduce \\
\hline coronavirus & $\begin{array}{l}-0.077 \\
(0.025)^{* *}\end{array}$ & $\begin{array}{l}-0.022 \\
(0.027)\end{array}$ & & & \\
\hline class ineq & & & $\begin{array}{l}-0.034 \\
(0.009)^{* * *}\end{array}$ & $\begin{array}{l}0.018 \\
(0.070)\end{array}$ & $\begin{array}{l}0.071 \\
(0.063)\end{array}$ \\
\hline natural ineq & & & $\begin{array}{l}0.002 \\
(0.009)\end{array}$ & $\begin{array}{l}-0.118 \\
(0.070)\end{array}$ & $\begin{array}{l}-0.075 \\
(0.063)\end{array}$ \\
\hline
\end{tabular}

Models w/ socio-demographic covariates

\begin{tabular}{|l|l|l|l|l|l|}
\hline & high deserve & low deserve & don't reduce & govt reduce & comps reduce \\
\hline coronavirus & $\begin{array}{l}-0.085 \\
(0.024)^{* * *}\end{array}$ & $\begin{array}{l}-0.022 \\
(0.026)\end{array}$ & & & \\
\hline class ineq & & & $\begin{array}{l}-0.037 \\
(0.009)^{* * *}\end{array}$ & $\begin{array}{l}0.061 \\
(0.063)\end{array}$ & $\begin{array}{l}0.102 \\
(0.060)\end{array}$ \\
\hline natural ineq & & & $\begin{array}{l}0.002 \\
(0.009)\end{array}$ & $\begin{array}{l}-0.123 \\
(0.063)\end{array}$ & $\begin{array}{l}-0.073 \\
(0.060)\end{array}$ \\
\hline
\end{tabular}

Note: The numbers inside the parentheses are standard errors. Stars denote $\mathrm{p}$-values: ${ }^{*} \mathrm{p}<0.1,{ }^{*} \mathrm{p}<0.05,{ }^{* *} \mathrm{p}<0.01,{ }^{* * *} \mathrm{p}<0.001$. Socio-demographic covariates include: age, gender, marital status, whether respondent has children living with them, race, religion, education level, employment status, household income, income volatility, political orientation, party preference, frequency of following the news, and degree of belief in the scientific community. 
Table 3. Does coronavirus amplify class effects? Inequality and opportunity perceptions.

Models w/o any socio-demographic covariates

\begin{tabular}{|l|l|l|l|l|l|}
\hline & enough opps & better opps & ineq problem & povty problem & hcare problem \\
\hline cor control & $\begin{array}{l}-0.008 \\
(0.031)\end{array}$ & $\begin{array}{l}-0.059 \\
(0.040)\end{array}$ & $\begin{array}{l}0.149 \\
(0.057)^{* *}\end{array}$ & $\begin{array}{l}0.119 \\
(0.050)^{*}\end{array}$ & $\begin{array}{l}0.134 \\
(0.056)^{*}\end{array}$ \\
\hline class ineq & $\begin{array}{l}-0.004 \\
(0.031)\end{array}$ & $\begin{array}{l}-0.013 \\
(0.039)\end{array}$ & $\begin{array}{l}0.136 \\
(0.056) *\end{array}$ & $\begin{array}{l}0.069 \\
(0.050)\end{array}$ & $\begin{array}{l}0.073 \\
(0.055)\end{array}$ \\
\hline cor class ineq & $\begin{array}{l}-0.061 \\
(0.031)\end{array}$ & $\begin{array}{l}-0.089 \\
(0.040)^{*}\end{array}$ & $\begin{array}{l}0.155 \\
(0.057)^{* *}\end{array}$ & $\begin{array}{l}0.127 \\
(0.050)^{*}\end{array}$ & $\begin{array}{l}0.164 \\
(0.056)^{* *}\end{array}$ \\
\hline nat ineq & $\begin{array}{l}-0.041 \\
(0.031)\end{array}$ & $\begin{array}{l}-0.046 \\
(0.040)\end{array}$ & $\begin{array}{l}0.030 \\
(0.057)\end{array}$ & $\begin{array}{l}0.046 \\
(0.050)\end{array}$ & $\begin{array}{l}-0.004 \\
(0.056)\end{array}$ \\
\hline cor nat ineq & $\begin{array}{l}-0.016 \\
(0.031)\end{array}$ & $\begin{array}{l}-0.003 \\
(0.040)\end{array}$ & $\begin{array}{l}0.078 \\
(0.056)\end{array}$ & $\begin{array}{l}0.036 \\
(0.050)\end{array}$ & $\begin{array}{l}0.075 \\
(0.055)\end{array}$ \\
\hline
\end{tabular}

Models w/ socio-demographic covariates

\begin{tabular}{|l|l|l|l|l|l|}
\hline & enough opps & better opps & ineq problem & povty problem & hcare problem \\
\hline cor control & $\begin{array}{l}-0.007 \\
(0.030)\end{array}$ & $\begin{array}{l}-0.057 \\
(0.038)\end{array}$ & $\begin{array}{l}0.113 \\
(0.051)^{*}\end{array}$ & $\begin{array}{l}0.085 \\
(0.046)^{*}\end{array}$ & $\begin{array}{l}0.094 \\
(0.050)\end{array}$ \\
\hline class ineq & $\begin{array}{l}-0.012 \\
(0.030)\end{array}$ & $\begin{array}{l}-0.022 \\
(0.038)\end{array}$ & $\begin{array}{l}0.130 \\
(0.051)^{*}\end{array}$ & $\begin{array}{l}0.061 \\
(0.046)\end{array}$ & $\begin{array}{l}0.062 \\
(0.050)\end{array}$ \\
\hline cor class ineq & $\begin{array}{l}-0.064 \\
(0.030)^{*}\end{array}$ & $\begin{array}{l}-0.091 \\
(0.039)^{*}\end{array}$ & $\begin{array}{l}0.162 \\
(0.051)^{* *}\end{array}$ & $\begin{array}{l}0.136 \\
(0.046)^{* *}\end{array}$ & $\begin{array}{l}0.166 \\
(0.050)^{* *}\end{array}$ \\
\hline nat ineq & $\begin{array}{l}-0.036 \\
(0.030)\end{array}$ & $\begin{array}{l}-0.046 \\
(0.038)\end{array}$ & $\begin{array}{l}0.007 \\
(0.051)\end{array}$ & $\begin{array}{l}0.023 \\
(0.046)\end{array}$ & $\begin{array}{l}-0.029 \\
(0.050)\end{array}$ \\
\hline cor nat ineq & $\begin{array}{l}-0.021 \\
(0.030)\end{array}$ & $\begin{array}{l}-0.019 \\
(0.038)\end{array}$ & $\begin{array}{l}0.063 \\
(0.051)\end{array}$ & $\begin{array}{l}0.020 \\
(0.046)\end{array}$ & $\begin{array}{l}0.054 \\
(0.050)\end{array}$ \\
\hline
\end{tabular}

Note: The numbers inside the parentheses are standard errors. Stars denote $\mathrm{p}$-values: ${ }^{\cdot} \mathrm{p}<0.1,{ }^{*} \mathrm{p}<0.05,{ }^{* *} \mathrm{p}<0.01,{ }^{* * *} \mathrm{p}<0.001$. Socio-demographic covariates include: age, gender, marital status, whether respondent has children living with them, race, religion, education level, employment status, household income, income volatility, political orientation, party preference, frequency of following the news, and degree of belief in the scientific community. 
Table 4. Does coronavirus amplify class effects? Policy preferences.

Models w/o any socio-demographic covariates

\begin{tabular}{|l|l|l|l|l|l|}
\hline & transfers eff & regulation eff & prog taxes eff & educ pols eff & priv charity eff \\
\hline cor control & $\begin{array}{l}0.085 \\
(0.057)\end{array}$ & $\begin{array}{l}-0.062 \\
(0.057)\end{array}$ & $\begin{array}{l}-0.011 \\
(0.056)\end{array}$ & $\begin{array}{l}0.004 \\
(0.053)\end{array}$ & $\begin{array}{l}0.052 \\
(0.054)\end{array}$ \\
\hline class ineq & $\begin{array}{l}0.066 \\
(0.057)\end{array}$ & $\begin{array}{l}0.088 \\
(0.057)\end{array}$ & $\begin{array}{l}0.011 \\
(0.056)\end{array}$ & $\begin{array}{l}0.124 \\
(0.053)^{*}\end{array}$ & $\begin{array}{l}0.133 \\
(0.054)^{*}\end{array}$ \\
\hline cor class ineq & $\begin{array}{l}0.209 \\
(0.057)^{* * *}\end{array}$ & $\begin{array}{l}0.100 \\
(0.057)\end{array}$ & $\begin{array}{l}0.075 \\
(0.056)\end{array}$ & $\begin{array}{l}0.103 \\
(0.053)\end{array}$ & $\begin{array}{l}0.093 \\
(0.054)\end{array}$ \\
\hline nat ineq & $\begin{array}{l}0.033 \\
(0.057)\end{array}$ & $\begin{array}{l}-0.003 \\
(0.057)\end{array}$ & $\begin{array}{l}-0.053 \\
(0.056)\end{array}$ & $\begin{array}{l}0.018 \\
(0.053)\end{array}$ & $\begin{array}{l}0.075 \\
(0.054)\end{array}$ \\
\hline cor nat ineq & $\begin{array}{l}0.027 \\
(0.057)\end{array}$ & $\begin{array}{l}-0.030 \\
(0.057)\end{array}$ & $\begin{array}{l}-0.012 \\
(0.056)\end{array}$ & $\begin{array}{l}0.010 \\
(0.053)\end{array}$ & $\begin{array}{l}-0.0001 \\
(0.054)\end{array}$ \\
\hline
\end{tabular}

Models w/ socio-demographic covariates

\begin{tabular}{|l|l|l|l|l|l|}
\hline & transfers eff & regulation eff & prog taxes eff & educ pols eff & priv charity eff \\
\hline cor control & $\begin{array}{l}0.062 \\
(0.054)\end{array}$ & $\begin{array}{l}-0.088 \\
(0.055)\end{array}$ & $\begin{array}{l}-0.038 \\
(0.052)\end{array}$ & $\begin{array}{l}-0.024 \\
(0.051)\end{array}$ & $\begin{array}{l}0.038 \\
(0.053)\end{array}$ \\
\hline class ineq & $\begin{array}{l}0.062 \\
(0.053)\end{array}$ & $\begin{array}{l}0.086 \\
(0.054)\end{array}$ & $\begin{array}{l}0.001 \\
(0.052)\end{array}$ & $\begin{array}{l}0.111 \\
(0.051)^{*}\end{array}$ & $\begin{array}{l}0.132 \\
(0.053)^{*}\end{array}$ \\
\hline cor class ineq & $\begin{array}{l}0.229 \\
(0.054)^{* * *}\end{array}$ & $\begin{array}{l}0.114 \\
(0.055)^{*}\end{array}$ & $\begin{array}{l}0.079 \\
(0.052)\end{array}$ & $\begin{array}{l}0.102 \\
(0.051)^{*}\end{array}$ & $\begin{array}{l}0.099 \\
(0.053)^{*}\end{array}$ \\
\hline nat ineq & $\begin{array}{l}0.051 \\
(0.054)\end{array}$ & $\begin{array}{l}0.011 \\
(0.054)\end{array}$ & $\begin{array}{l}-0.052 \\
(0.052)\end{array}$ & $\begin{array}{l}0.020 \\
(0.051)\end{array}$ & $\begin{array}{l}0.094 \\
(0.053)\end{array}$ \\
\hline cor nat ineq & $\begin{array}{l}0.017 \\
(0.054)\end{array}$ & $\begin{array}{l}-0.040 \\
(0.054)\end{array}$ & $\begin{array}{l}-0.024 \\
(0.052)\end{array}$ & -0.012 & $(0.051)$ \\
\hline
\end{tabular}

Note: The numbers inside the parentheses are standard errors. Stars denote $\mathrm{p}$-values: ${ }^{\circ} \mathrm{p}<0.1,{ }^{*} \mathrm{p}<0.05,{ }^{* *} \mathrm{p}<0.01,{ }^{* * *} \mathrm{p}<0.001$. Socio-demographic covariates include: age, gender, marital status, whether respondent has children living with them, race, religion, education level, employment status, household income, income volatility, political orientation, party preference, frequency of following the news, and degree of belief in the scientific community. 


\section{Appendix A: Experimental texts, images, videos, and other related content}

Those interested in seeing how the survey looked like from the respondents' perspective can take the survey for themselves by going to this link [LINK REMOVED FOR BLIND REVIEW]. The complete set of texts and figures as well as links to the videos used in the experiment are provided below.

Many of the questions and text used in this survey are taken directly or adapted from

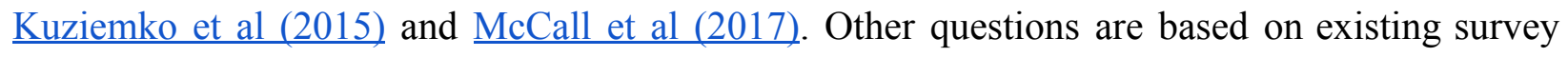
questions from the General Social Survey (GSS), World Values Survey (WVS), Polish Panel Survey (POLPAN), or are written by the researcher.

\section{Welcome to our survey!}

The goal of this survey is to understand the public's opinions regarding important societal and economic trends in the US.

At no point in the survey should you feel obligated to answer in a particular way; the most important factor for the success of our research is that you answer honestly. Anytime you don't know an answer, just give your best guess.

It is also very important for the success of our research project that you complete the survey until the end, once you have started. This survey should take (on average) about 10 to 15 minutes to complete.

Notes:

Your participation in this study is purely voluntary, and you may withdraw your participation or your data at any time without any penalty to you. Your name will never be recorded. Results may include summary data, but you will never be identified. If you have any questions about this study, you may contact us at [EMAIL ADDRESS REMOVED FOR BLIND REVIEW].

\section{YOU MUST BE A US RESIDENT TO PARTICIPATE IN THIS SURVEY}

- Yes, I would like to take part in this study, and confirm that I AM A US RESIDENT and am 18 or older

- No, I would not like to participate

IF ANSWER $=$ Yes

CONTINUE

ELSE

END SURVEY 


\section{Video and Quiz}

We'll start by showing you a short video to assess your comprehension skills.

A short paragraph will be narrated in the video, so be prepared to watch a short clip with subtitles. Simply press [YouTube play symbol] to start the video.

After you watch the video, you will be asked a question about it. 
IF CONDITION = Control

The internet that many of us now take for granted came into existence less than forty years ago. In fact, it did not start taking its familiar form as a collection of web pages until thirty years ago. Since then, the internet has become an integral part of many aspects of our lives, including information gathering, banking, and entertainment.

THIS TEXT IS PRESENTED TO RESPONDENTS IN AN UNLISTED YOUTUBE VIDEO WITH SUBTITLES AND THE FOLLOWING LICENSED ADOBE STOCK IMAGE IN THE BACKGROUND.

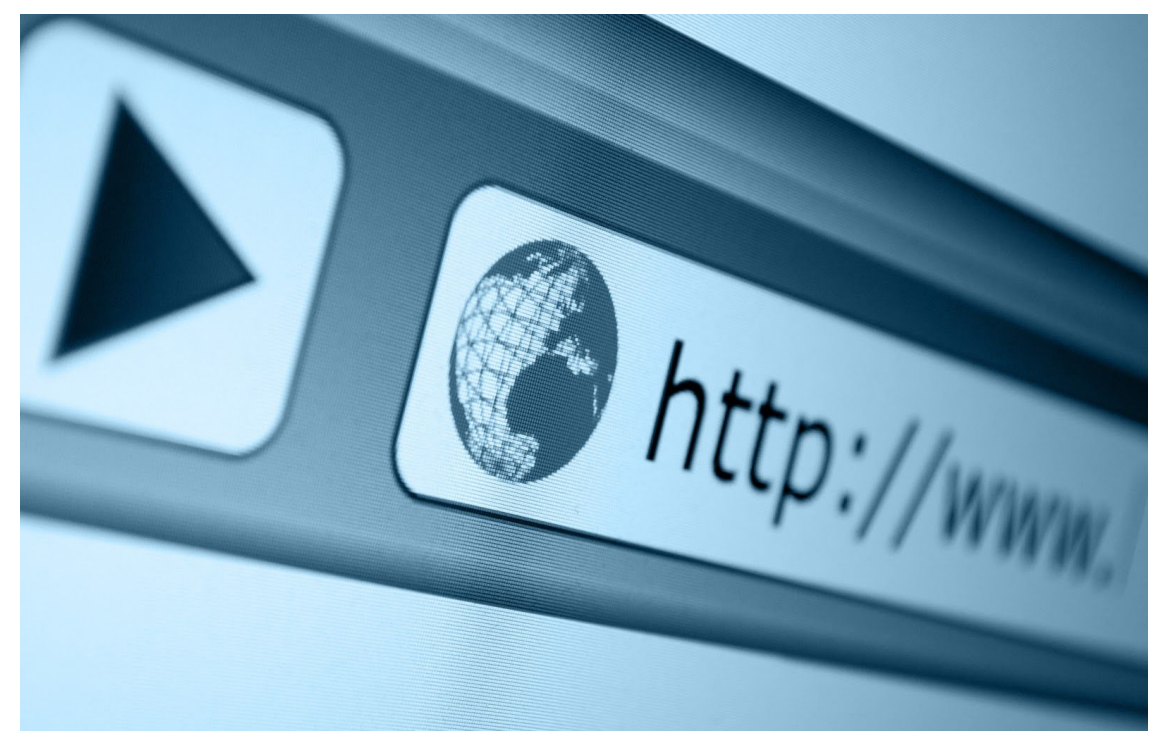

(c) jamdesign 


\section{IF CONDITION = Natural inequality}

Millions of Americans have serious medical conditions, including heart disease, cancer, and diabetes. The risk of having a medical condition increases with age. In addition, elderly people usually have weakened immune systems. While the elderly are at greater risk, millions of younger Americans also suffer from these conditions.

THIS TEXT IS PRESENTED TO RESPONDENTS IN AN UNLISTED YOUTUBE VIDEO WITH SUBTITLES AND THE FOLLOWING LICENSED ADOBE STOCK IMAGE IN THE BACKGROUND.

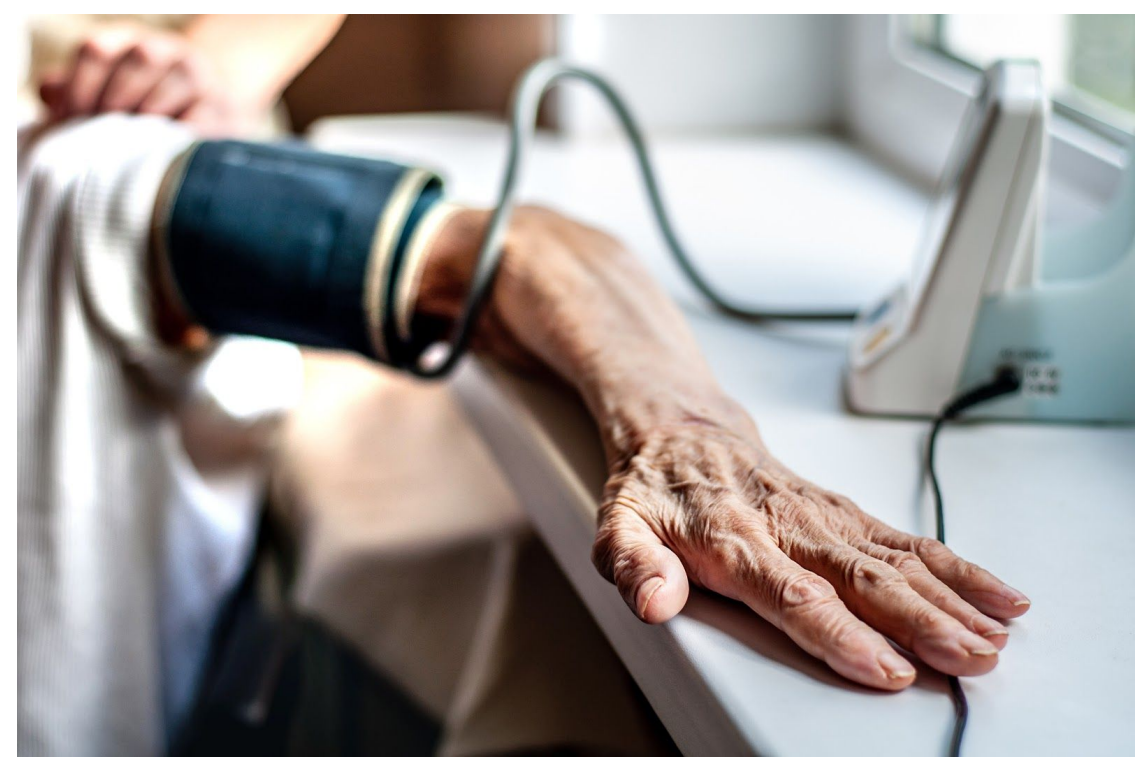

(C) alonaphoto 
Millions of Americans live in poverty. Many more make less than twice the poverty threshold. The fraction of low-income households is higher among minorities such as blacks and Hispanics. Low-income people face difficulties in many areas, including food, housing, and healthcare, that high-income Americans take for granted.

THIS TEXT IS PRESENTED TO RESPONDENTS IN AN UNLISTED YOUTUBE VIDEO WITH SUBTITLES AND THE FOLLOWING LICENSED ADOBE STOCK IMAGE IN THE BACKGROUND.

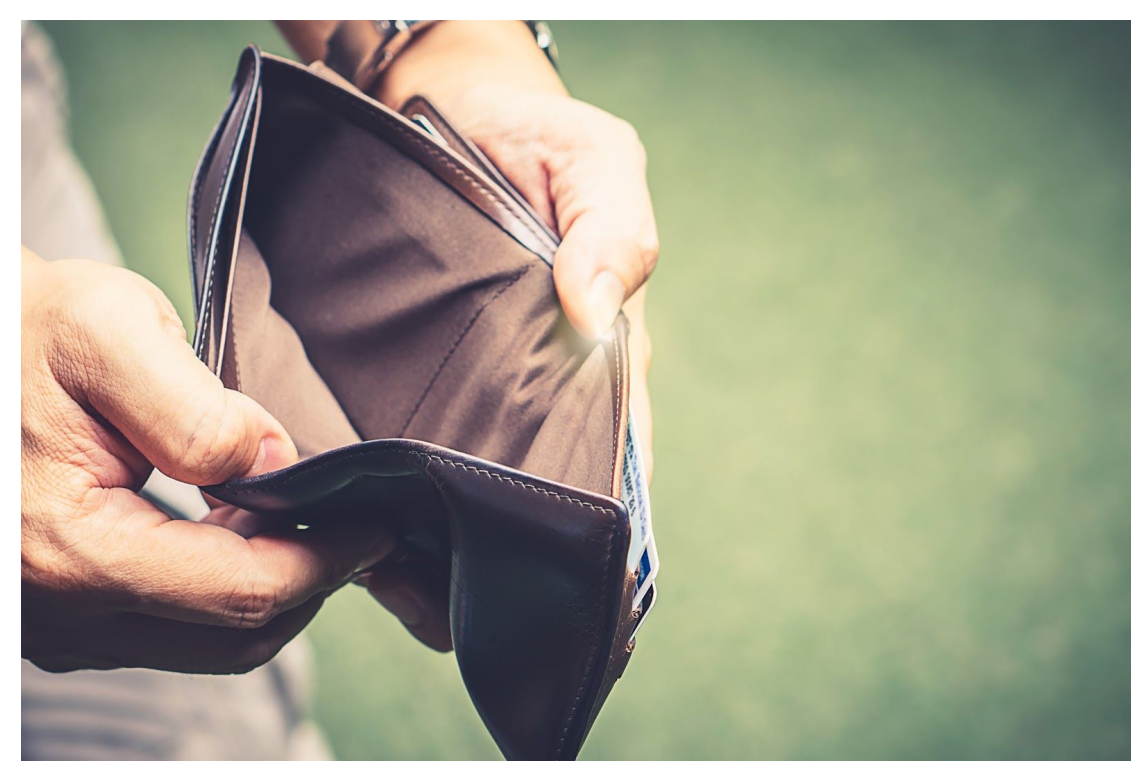

(c) Chan2545 
We are in the midst of a global disease outbreak. Within a few months after its emergence, the new coronavirus (COVID-19) has spread to almost every country on earth, including the US. Very few events in history have impacted the entirety of humanity in this way, regardless of sex, race, or cultural background.

THIS TEXT IS PRESENTED TO RESPONDENTS IN AN UNLISTED YOUTUBE VIDEO WITH SUBTITLES AND THE FOLLOWING LICENSED ADOBE STOCK IMAGE IN THE BACKGROUND.

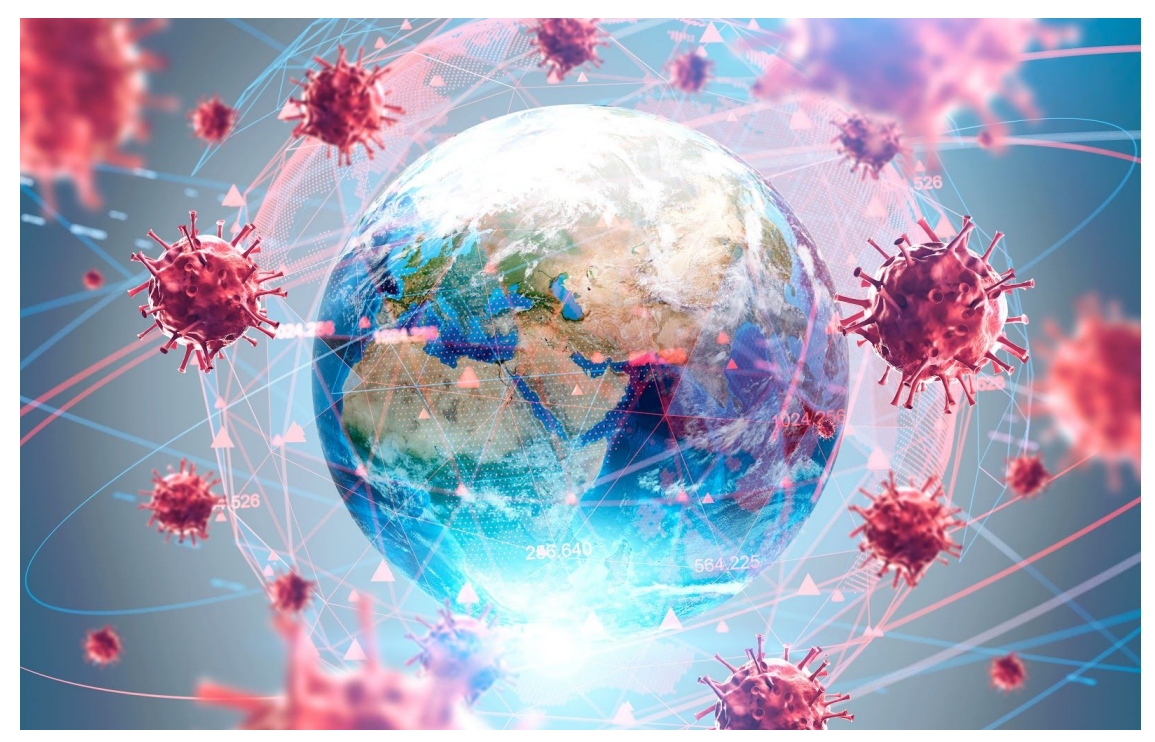

(C) denisismagilov 
IF CONDITION = Coronavirus natural inequality

The new coronavirus (COVID-19) is not affecting everyone in the same way. The elderly and those with underlying medical conditions such as heart disease, cancer, and diabetes have been disproportionately affected. The number of infections and deaths are significantly higher among this group compared to the rest of the population.

THIS TEXT IS PRESENTED TO RESPONDENTS IN AN UNLISTED YOUTUBE VIDEO WITH SUBTITLES AND THE FOLLOWING LICENSED ADOBE STOCK IMAGE IN THE BACKGROUND.

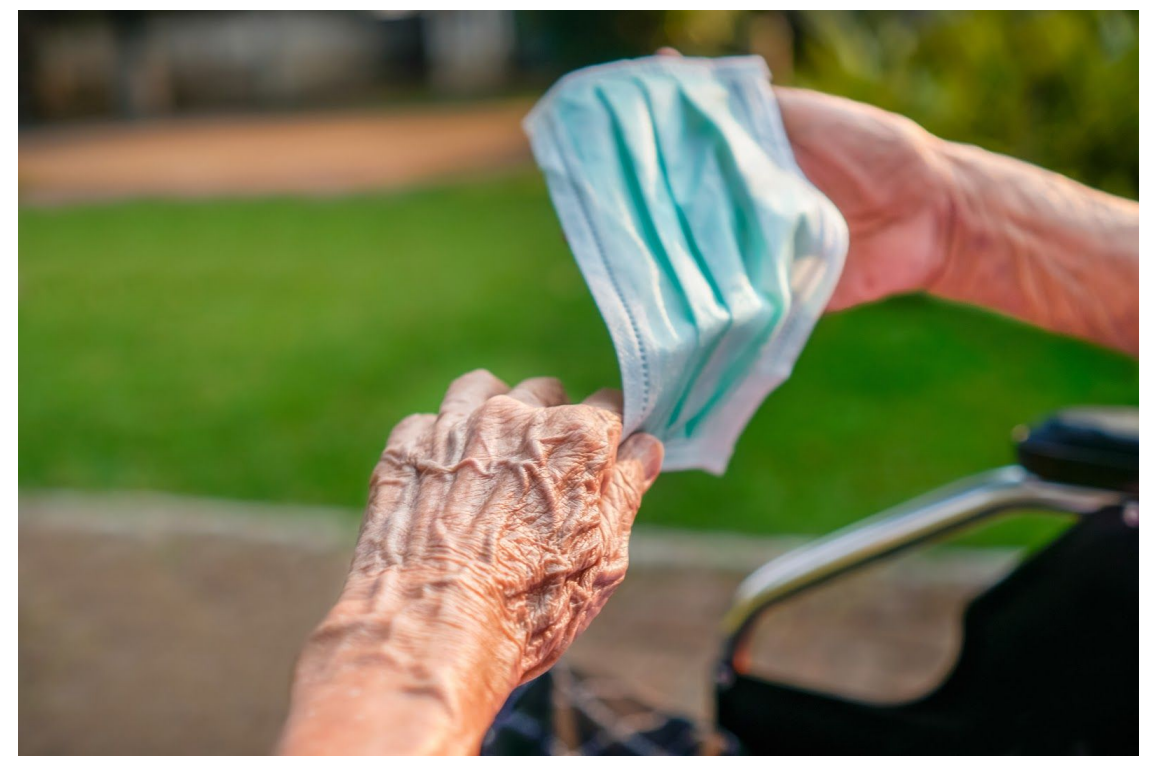

(c) toa555 
IF CONDITION = Coronavirus class inequality

The new coronavirus (COVID-19) is not affecting everyone in the same way. Poor and low-income communities, particularly minorities such as blacks and Hispanics, have been disproportionately affected. The number of infections and deaths are significantly higher among this group compared to the rest of the population.

THIS TEXT IS PRESENTED TO RESPONDENTS IN AN UNLISTED YOUTUBE VIDEO WITH SUBTITLES AND THE FOLLOWING LICENSED ADOBE STOCK IMAGE IN THE BACKGROUND.

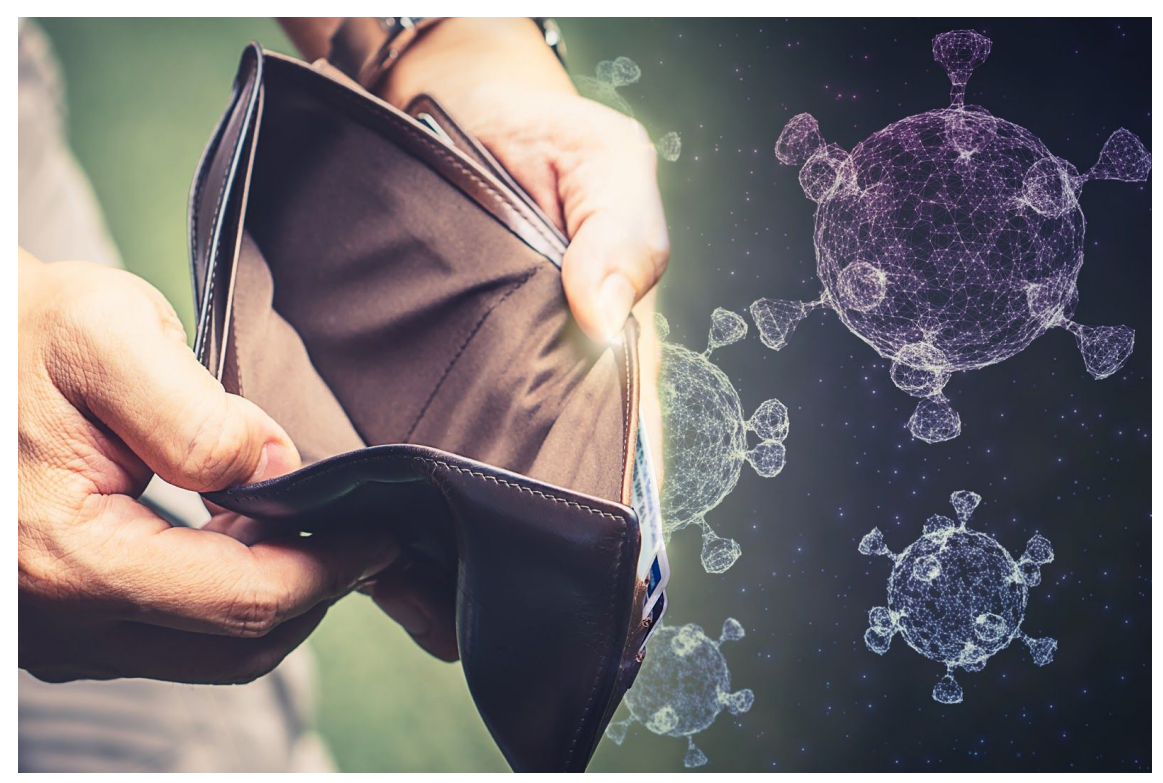

(c) Chan2545 
Describe in your own words what the text you just listened to was about. [A couple of words or a sentence is enough.]

TEXT ENTRY HERE 
Thank you for answering the text comprehension question.

Now, we'll be asking you a few questions regarding your opinions on certain matters.

QUESTIONS ARE PRESENTED IN A RANDOM ORDER.

CHOICES ARE ALSO RANDOMIZED (STANDARD, REVERSED). 
Please indicate how important you think each of the following is in terms of getting ahead in life.

How important is coming from a wealthy family for getting ahead in life?

- Essential

- Very important

- Fairly important

- Not very important

- Not important at all

How important is having well-educated parents for getting ahead in life?

- Essential

- Very important

- Fairly important

- Not very important

- Not important at all

How important is having ambition for getting ahead in life?

- Essential

- Very important

- Fairly important

- Not very important

- Not important at all

How important is hard work for getting ahead in life?

- Essential

- Very important

- Fairly important

- Not very important

- Not important at all

How important is innate ability and talent for getting ahead in life?

- Essential

- Very important

- Fairly important

- Not very important 
- Not important at all

How important is luck for getting ahead in life?

- Essential

- Very important

- Fairly important

- Not very important

- Not important at all

How important is knowing the right people for getting ahead in life?

- Essential

- Very important

- Fairly important

- Not very important

- Not important at all

How important is a good education for getting ahead in life?

- Essential

- Very important

- Fairly important

- Not very important

- Not important at all

How important is political influence for getting ahead in life?

- Essential

- Very important

- Fairly important

- Not very important

- Not important at all 
Do you think Americans today have enough opportunities for getting ahead in life?

- No or very little opportunity

- Some opportunity

- Plenty of opportunity

Do you think Americans today have more or less opportunities for getting ahead in life compared to their parents?

- More

- Same

- Less 
Do you think hard work or luck and connections is more important for achieving success in life?

1 - In the long run, hard work usually brings a better life

2

3

4

5

6

7 - Hard work doesn't generally bring success-it's more a matter of luck and connections

Do you think people are poor because of laziness and lack of willpower or because of an unfair society?

1 - People are poor because of laziness and lack of willpower

2

3

4

5

6

7 - People are poor because of an unfair society 
Do you think that high earners in our society deserve their high incomes?

- Always

- Most of the time

- Sometimes

- Rarely

- Never

Do you think that low earners in our society deserve their low incomes?

- Always

- Most of the time

- Sometimes

- Rarely

- Never 
Do you think income inequality is a serious problem in America?

- Not a problem at all

- A small problem

- A problem

- A serious problem

- A very serious problem

Do you think poverty is a serious problem in America?

- Not a problem at all

- A small problem

- A problem

- A serious problem

- A very serious problem

Do you think unequal access to healthcare is a serious problem in America?

- Not a problem at all

- A small problem

- A problem

- A serious problem

- A very serious problem 
Do you think the income gap between richer and poorer Americans is decreasing or increasing?

- Decreasing

- Same

- Increasing 
Do you think government regulation (e.g., minimum wage, caps on top compensation) is an effective tool to address economic inequality in the US?

1 - Extremely effective

2

3

4

5 - Not at all effective

Do you think government transfers (food stamps, Medicaid) is an effective tool to address economic inequality in the US?

1 - Extremely effective

2

3

4

5 - Not at all effective

Do you think progressive taxes is an effective tool to address economic inequality in the US?

1 - Extremely effective

2

3

4

5 - Not at all effective

Do you think education policies is an effective tool to address economic inequality in the US?

1 - Extremely effective

2

3

4

5 - Not at all effective

Do you think private charity is an effective tool to address economic inequality in the US?

1 - Extremely effective

2 
3

4

5 - Not at all effective 
Do you think the government should reduce the income differences between rich and poor?

1 - The government should not concern itself with reducing income differences

2

3

4

5

6

7 - The government ought to reduce the income differences between rich and poor-perhaps by raising the taxes of wealthy families or by giving income assistance to the poor

Do you think major companies should reduce the pay differences between employees with high pay and those with low pay?

1 - Major companies should not concern themselves with reducing pay differences

2

3

4

5

6

7 - Major companies ought to reduce the pay differences between employees with high pay and those with low pay-perhaps by reducing the pay of executives or by increasing the pay of unskilled workers

Which of the following groups do you think has the greatest responsibility for reducing differences in income between those with high incomes and those with low incomes?

- Government

- Major companies

- Private charities

- High income individuals themselves

- Low income individuals themselves

- Income differences do not need to be reduced 
Next, please answer the following standard demographic questions. 
Are you a US resident?

- Yes

- No

In which state do you currently reside?

DROP-DOWN LIST OF STATES HERE 
What is your gender?

- Male

- Female

- Other

What is your age? [Enter a number (e.g., 35)]

TEXT ENTRY HERE

What is your marital status?

- Single

- Married

Do you have children living with you?

- Yes

- No 
How would you describe your ethnicity/race?

- European American/White

- African American/Black

- Hispanic/Latino

- Asian/Asian American

- Other

How would you describe your religion?

- Christian (Protestant)

- Christian (Catholic)

- Christian (Mormon)

- Christian (Other)

- Jewish

- Muslim

- Hindu

- Buddhist

- Other religion

- No religion

Which category best describes your highest level of education?

- Eighth Grade or Less

- Some High School

- High School Degree/GED

- Some College

- 2-year College Degree

- 4-year College Degree

- Master's Degree

- Doctoral Degree

- Professional Degree (JD, MD, MBA) 
What is your current employment status?

- Full-time employee

- Part-time employee

- Self-employed or small business owner

- Unemployed and looking for work

- Student

- Not in labor force (for example: retired, or full-time parent)

What is your occupation?

TEXT ENTRY HERE 
What was your TOTAL household income, before taxes, last year?

- $\$ 0-\$ 9,999$

- $\$ 10,000-\$ 14,999$

- $\$ 15,000-\$ 19,999$

- $\$ 20,000-\$ 29,999$

- $\$ 30,000-\$ 39,999$

- $\$ 40,000-\$ 49,999$

- $\$ 50,000-\$ 74,999$

- $\$ 75,000-\$ 99,999$

- $\$ 100,000-\$ 124,999$

- $\$ 125,000-\$ 149,999$

- $\$ 150,000-\$ 199,999$

- $\$ 200,000+$

Compared with American families in general today, would you say your family income is above or below average?

- Far below average

- Below average

- Average

- Above average

- Far above average

Which best describes your household's income each month?

- Income is about the same each month

- Income varies somewhat from month to month

- Income varies a lot from month to month 
Compared to 10 years ago, do you think your standard of living now is better or worse?

- Much better

- Somewhat better

- About the same

- Somewhat worse

- Much worse

10 years into the future, do you think your standard of living will be better or worse?

- Much better

- Somewhat better

- About the same

- Somewhat worse

- Much worse 
On economic policy matters, where do you see yourself on the liberal/conservative spectrum?

- Very conservative

- Conservative

- Moderate

- Liberal

- Very liberal

Generally speaking, do you usually think of yourself as a Republican, a Democrat, an Independent, or what?

- Republican

- Democrat

- Independent

- None 
How often do you follow the news?

- Every day

- A few times a week

- Once a week

- Less than once a week

- Never

How much confidence do you have in the scientific community?

- A great deal of confidence

- Only some confidence

- Hardly any confidence at all 
Now, we have a few quick questions about your parents. 
What kind of work did your father normally do while you were growing up? That is, what was his job called?

TEXT ENTRY HERE

What kind of work did your mother usually do while you were growing up? That is, what was her job called?

TEXT ENTRY HERE 
Which category best describes your father's highest level of education?

- Eighth Grade or Less

- Some High School

- High School Degree/GED

- Some College

- 2-year College Degree

- 4-year College Degree

- Master's Degree

- Doctoral Degree

- Professional Degree (JD, MD, MBA)

- Not Applicable

Which category best describes your mother's highest level of education?

- Eighth Grade or Less

- Some High School

- High School Degree/GED

- Some College

- 2-year College Degree

- 4-year College Degree

- Master's Degree

- Doctoral Degree

- Professional Degree (JD, MD, MBA)

- Not Applicable 
Thinking about the time when you were 16 years old, compared with American families in general then, would you say your family income was above or below average?

- Far below average

- Below average

- Average

- Above average

- Far above average

- Not Applicable

Compared to your parents when they were the age you are now, do you think your own standard of living now is better or worse than theirs was?

- Much better

- Somewhat better

- About the same

- Somewhat worse

- Much worse

- Not Applicable 
Finally, please answer the following questions related to the coronavirus outbreak. 
Do you think the coronavirus is a serious threat to the American people?

- Not a threat at all

- A small threat

- A threat

- A serious threat

- A very serious threat

Do you think it is more important to save lives or to save the economy during this outbreak?

- 1 - Saving lives must be the priority even if it means the economy will suffer

- 2

- 3

- 4

- 5 - Saving the economy must be the priority even if it means lives will be lost

On the whole, how satisfied are you with the way your city has been handling the coronavirus situation?

- Very satisfied

- Fairly satisfied

- Neither satisfied nor dissatisfied

- Not very satisfied

- Not satisfied at all

On the whole, how satisfied are you with the way your state has been handling the coronavirus situation?

- Very satisfied

- Fairly satisfied

- Neither satisfied nor dissatisfied

- Not very satisfied

- Not satisfied at all

On the whole, how satisfied are you with the way the federal government has been handling the coronavirus situation?

- Very satisfied

- Fairly satisfied

- Neither satisfied nor dissatisfied 
- Not very satisfied

- Not satisfied at all

How have you been affected by the coronavirus? [Select all that apply.]

- I contracted coronavirus and became ill.

- I lost my job because of coronavirus.

- I experienced a significant decrease in income due to coronavirus.

- I have an underlying medical condition that puts me at greater risk for severe illness.

- Someone in my family contracted coronavirus and became ill.

- Someone in my family lost their job because of coronavirus.

- Someone in my family experienced a significant decrease in income due to coronavirus.

- Someone in my family has an underlying medical condition that puts them at greater risk for severe illness.

- I have not been affected by coronavirus in any major way.

- Other (please specify)

How many days have you been outside in the past seven days?

0

1

2

3

4

5

6 


\section{THE TEXT BELOW IS SHOWN TO RESPONDENTS BECAUSE IRB REQUIRES IT}

After submitting your responses, you can protect your privacy by clearing your browser's history, cache, cookies, and other browsing data. (Warning: This will log you out of online services.) 


\section{Appendix B: Sample size calculations and sample characteristics}

\section{Sample size calculations}

Sample size calculations were made with the aim of being able to detect a small effect in one-way ANOVA. The pwr. anova. test function in the $\mathbf{R}$ package pwr was used for this end. Using this function, and assuming a small effect size (Cohen's $d=0.05$ ), a total of 5,200 respondents gives us more than $80 \%$ power to be able to detect the effect of interest. (Note that Cohen's $d$ is defined as mu/sigma, where mu is the raw effect size in the original scale and sigma is the standard deviation of the outcome variable.) The specific function that was run was this: pwr.anova. test $(k=6, f=0.05$, sig. level=0.05, power $=0.8)$.

\section{Sample characteristics}

Table B1 presents sample sizes by condition, Table B2 presents summary socio-demographics by condition, and Table B3 presents the distribution of respondents across states by condition.

Table B1. Number of respondents by experimental condition.

\begin{tabular}{|l|l|}
\hline Experimental condition & Number of respondents \\
\hline Control & 874 \\
\hline Class inequality & 885 \\
\hline Natural inequality & 873 \\
\hline Coronavirus control & 870 \\
\hline Coronavirus class inequality & 867 \\
\hline Coronavirus natural inequality & 880 \\
\hline Total & 5,249 \\
\hline
\end{tabular}

Table B2. Socio-demographic characteristics by experimental condition.

\begin{tabular}{|l|l|l|l|l|l|l|}
\hline & control & class & natural & cor_cntrl & cor_class & cor_natural \\
\hline Age & 45.0 & 45.2 & 46.5 & 45.6 & 45.8 & 44.9 \\
\hline Gender & & & & & & \\
Male & 0.471 & 0.484 & 0.473 & 0.452 & 0.490 & 0.464 \\
Female & 0.523 & 0.511 & 0.523 & 0.539 & 0.504 & 0.527 \\
Other & 0.006 & 0.006 & 0.003 & 0.009 & 0.006 & 0.009 \\
\hline Marital status & & & & & & \\
Single & 0.519 & 0.533 & 0.530 & 0.509 & 0.521 & 0.523 \\
Married & 0.481 & 0.467 & 0.470 & 0.491 & 0.479 & 0.477 \\
\hline Has children living with them & & & & & & \\
\hline
\end{tabular}




\begin{tabular}{|c|c|c|c|c|c|c|}
\hline No & 0.634 & 0.635 & 0.648 & 0.624 & 0.645 & 0.649 \\
\hline Yes & 0.366 & 0.365 & 0.352 & 0.376 & 0.355 & 0.351 \\
\hline \multicolumn{7}{|l|}{ Ethnicity/race } \\
\hline European American/White & 0.688 & 0.681 & 0.692 & 0.697 & 0.691 & 0.667 \\
\hline African American/Black & 0.127 & 0.128 & 0.135 & 0.125 & 0.119 & 0.119 \\
\hline Hispanic/Latino & 0.085 & 0.094 & 0.086 & 0.091 & 0.095 & 0.111 \\
\hline Asian/Asian American & 0.070 & 0.048 & 0.066 & 0.053 & 0.053 & 0.073 \\
\hline Other & 0.031 & 0.050 & 0.021 & 0.035 & 0.043 & 0.030 \\
\hline \multicolumn{7}{|l|}{ Religion } \\
\hline Christian (Protestant) & 0.285 & 0.269 & 0.273 & 0.268 & 0.254 & 0.244 \\
\hline Christian (Catholic) & 0.241 & 0.253 & 0.227 & 0.239 & 0.255 & 0.243 \\
\hline Christian (Mormon) & 0.017 & 0.017 & 0.012 & 0.025 & 0.015 & 0.017 \\
\hline Christian (Other) & 0.114 & 0.122 & 0.143 & 0.130 & 0.137 & 0.157 \\
\hline Jewish & 0.028 & 0.034 & 0.038 & 0.032 & 0.042 & 0.027 \\
\hline Muslim & 0.021 & 0.019 & 0.013 & 0.018 & 0.019 & 0.014 \\
\hline Hindu & 0.008 & 0.008 & 0.003 & 0.006 & 0.003 & 0.015 \\
\hline Buddhist & 0.008 & 0.010 & 0.009 & 0.012 & 0.008 & 0.013 \\
\hline Other religion & 0.057 & 0.058 & 0.054 & 0.048 & 0.048 & 0.052 \\
\hline No religion & 0.221 & 0.210 & 0.229 & 0.222 & 0.219 & 0.218 \\
\hline \multicolumn{7}{|l|}{ Highest level of education } \\
\hline Eighth Grade or Less & 0.006 & 0.003 & 0.003 & 0.005 & 0.006 & 0.003 \\
\hline Some High School & 0.031 & 0.031 & 0.024 & 0.025 & 0.017 & 0.036 \\
\hline High School Degree/GED & 0.203 & 0.190 & 0.183 & 0.193 & 0.203 & 0.207 \\
\hline Some College & 0.247 & 0.232 & 0.225 & 0.224 & 0.209 & 0.232 \\
\hline 2-year College Degree & 0.103 & 0.124 & 0.118 & 0.110 & 0.104 & 0.112 \\
\hline 4-year College Degree & 0.244 & 0.251 & 0.275 & 0.264 & 0.283 & 0.226 \\
\hline Master's Degree & 0.113 & 0.131 & 0.124 & 0.136 & 0.131 & 0.134 \\
\hline Doctoral Degree & 0.020 & 0.017 & 0.015 & 0.015 & 0.020 & 0.014 \\
\hline Professional Degree (JD, MD, MBA) & 0.034 & 0.022 & 0.033 & 0.028 & 0.028 & 0.035 \\
\hline \multicolumn{7}{|l|}{ Employment status } \\
\hline Full-time employee & 0.413 & 0.407 & 0.379 & 0.390 & 0.403 & 0.417 \\
\hline Part-time employee & 0.098 & 0.090 & 0.101 & 0.106 & 0.105 & 0.101 \\
\hline Self-employed or small business owner & 0.084 & 0.066 & 0.065 & 0.066 & 0.070 & 0.066 \\
\hline Unemployed and looking for work & 0.102 & 0.092 & 0.110 & 0.107 & 0.105 & 0.097 \\
\hline Student & 0.050 & 0.062 & 0.058 & 0.060 & 0.058 & 0.057 \\
\hline Not in labor force & 0.253 & 0.284 & 0.286 & 0.272 & 0.260 & 0.262 \\
\hline \multicolumn{7}{|l|}{ Total household income before taxes } \\
\hline$\$ 0-\$ 9,999$ & 0.050 & 0.081 & 0.061 & 0.069 & 0.060 & 0.076 \\
\hline$\$ 10,000-\$ 14,999$ & 0.061 & 0.054 & 0.055 & 0.064 & 0.039 & 0.049 \\
\hline$\$ 15,000-\$ 19,999$ & 0.049 & 0.051 & 0.050 & 0.055 & 0.053 & 0.047 \\
\hline$\$ 20,000-\$ 29,999$ & 0.098 & 0.099 & 0.119 & 0.087 & 0.103 & 0.103 \\
\hline$\$ 30,000-\$ 39,999$ & 0.102 & 0.106 & 0.104 & 0.107 & 0.125 & 0.094 \\
\hline$\$ 40,000-\$ 49,999$ & 0.108 & 0.081 & 0.094 & 0.093 & 0.093 & 0.089 \\
\hline$\$ 50,000-\$ 74,999$ & 0.182 & 0.169 & 0.187 & 0.184 & 0.183 & 0.195 \\
\hline$\$ 75,000-\$ 99,999$ & 0.122 & 0.142 & 0.112 & 0.139 & 0.128 & 0.122 \\
\hline
\end{tabular}




\begin{tabular}{|c|c|c|c|c|c|c|}
\hline$\$ 100,000-\$ 124,999$ & 0.086 & 0.063 & 0.071 & 0.064 & 0.075 & 0.077 \\
\hline$\$ 125,000-\$ 149,999$ & 0.062 & 0.067 & 0.065 & 0.055 & 0.047 & 0.061 \\
\hline$\$ 150,000-\$ 199,999$ & 0.047 & 0.052 & 0.048 & 0.047 & 0.044 & 0.057 \\
\hline$\$ 200,000+$ & 0.033 & 0.033 & 0.033 & 0.035 & 0.050 & 0.030 \\
\hline \multicolumn{7}{|l|}{ Income volatility } \\
\hline Income is about the same each month & 0.619 & 0.641 & 0.640 & 0.634 & 0.612 & 0.611 \\
\hline Income varies somewhat from month to month & 0.289 & 0.258 & 0.257 & 0.282 & 0.293 & 0.280 \\
\hline Income varies a lot from month to month & 0.092 & 0.102 & 0.103 & 0.084 & 0.095 & 0.109 \\
\hline \multicolumn{7}{|l|}{ Liberal/conservative spectrum } \\
\hline Very conservative & 0.106 & 0.123 & 0.108 & 0.113 & 0.104 & 0.130 \\
\hline Conservative & 0.200 & 0.184 & 0.210 & 0.205 & 0.204 & 0.188 \\
\hline Moderate & 0.430 & 0.435 & 0.419 & 0.410 & 0.443 & 0.432 \\
\hline Liberal & 0.177 & 0.175 & 0.183 & 0.186 & 0.153 & 0.176 \\
\hline Very liberal & 0.086 & 0.083 & 0.080 & 0.086 & 0.096 & 0.075 \\
\hline \multicolumn{7}{|l|}{ Party identity } \\
\hline Republican & 0.344 & 0.337 & 0.310 & 0.330 & 0.343 & 0.318 \\
\hline Democrat & 0.383 & 0.359 & 0.400 & 0.393 & 0.322 & 0.375 \\
\hline Independent & 0.219 & 0.247 & 0.246 & 0.236 & 0.263 & 0.234 \\
\hline None & 0.054 & 0.057 & 0.044 & 0.041 & 0.073 & 0.073 \\
\hline \multicolumn{7}{|l|}{ Frequency of following news } \\
\hline Never & 0.028 & 0.028 & 0.026 & 0.025 & 0.022 & 0.030 \\
\hline Less than once a week & 0.080 & 0.075 & 0.071 & 0.084 & 0.077 & 0.073 \\
\hline Once a week & 0.116 & 0.085 & 0.116 & 0.095 & 0.116 & 0.103 \\
\hline A few times a week & 0.269 & 0.302 & 0.276 & 0.240 & 0.268 & 0.275 \\
\hline Every day & 0.508 & 0.511 & 0.511 & 0.555 & 0.517 & 0.519 \\
\hline \multicolumn{7}{|l|}{ Confidence in the scientific community } \\
\hline Hardly any confidence at all & 0.090 & 0.081 & 0.079 & 0.070 & 0.087 & 0.080 \\
\hline Only some confidence & 0.470 & 0.440 & 0.468 & 0.437 & 0.449 & 0.436 \\
\hline A great deal of confidence & 0.439 & 0.479 & 0.452 & 0.493 & 0.465 & 0.484 \\
\hline
\end{tabular}

Age is in years. All other numbers presented are proportions.

Table B3. Number of respondents in each state by experimental condition.

\begin{tabular}{|l|l|l|l|l|l|l|}
\hline State & control & class & natural & cor_cntrl & cor_class & cor_natural \\
\hline Alabama & 14 & 13 & 12 & 12 & 18 & 14 \\
Alaska & 3 & 3 & 0 & 1 & 2 & 1 \\
Arizona & 23 & 14 & 23 & 14 & 20 & 26 \\
Arkansas & 3 & 8 & 13 & 10 & 6 & 8 \\
California & 86 & 88 & 100 & 95 & 86 & 87 \\
Colorado & 14 & 12 & 13 & 14 & 12 & 15 \\
Connecticut & 10 & 9 & 9 & 6 & 12 & 14 \\
Delaware & 2 & 3 & 5 & 4 & 1 & 4 \\
District of Columbia & 3 & 3 & 2 & 4 & 3 & 3 \\
Florida & 90 & 72 & 74 & 71 & 85 \\
\hline
\end{tabular}




\begin{tabular}{|c|c|c|c|c|c|c|}
\hline Georgia & 35 & 30 & 29 & 21 & 33 & 29 \\
\hline Hawaii & 5 & 4 & 3 & 3 & 2 & 4 \\
\hline Idaho & 2 & 4 & 4 & 7 & 4 & 1 \\
\hline Illinois & 45 & 41 & 37 & 41 & 37 & 41 \\
\hline Indiana & 11 & 24 & 10 & 32 & 7 & 10 \\
\hline Iowa & 8 & 7 & 4 & 5 & 6 & 8 \\
\hline Kansas & 6 & 11 & 6 & 8 & 10 & 3 \\
\hline Kentucky & 9 & 13 & 11 & 12 & 6 & 13 \\
\hline Louisiana & 11 & 9 & 10 & 13 & 10 & 7 \\
\hline Maine & 5 & 2 & 2 & 5 & 5 & 5 \\
\hline Maryland & 15 & 17 & 8 & 9 & 19 & 22 \\
\hline Massachusetts & 16 & 18 & 15 & 22 & 14 & 16 \\
\hline Michigan & 26 & 14 & 23 & 22 & 22 & 35 \\
\hline Minnesota & 7 & 9 & 13 & 14 & 14 & 8 \\
\hline Mississippi & 6 & 8 & 11 & 10 & 3 & 8 \\
\hline Missouri & 11 & 18 & 8 & 11 & 9 & 16 \\
\hline Montana & 4 & 1 & 1 & 3 & 5 & 1 \\
\hline Nebraska & 6 & 3 & 3 & 5 & 2 & 4 \\
\hline Nevada & 20 & 11 & 14 & 7 & 13 & 10 \\
\hline New Hampshire & 4 & 3 & 4 & 2 & 2 & 3 \\
\hline New Jersey & 31 & 31 & 25 & 28 & 31 & 33 \\
\hline New Mexico & 5 & 3 & 1 & 5 & 6 & 6 \\
\hline New York & 63 & 66 & 73 & 76 & 77 & 54 \\
\hline North Carolina & 22 & 37 & 33 & 26 & 28 & 23 \\
\hline North Dakota & 4 & 0 & 3 & 0 & 0 & 2 \\
\hline Ohio & 33 & 37 & 34 & 23 & 27 & 23 \\
\hline Oklahoma & 7 & 7 & 9 & 6 & 13 & 4 \\
\hline Oregon & 8 & 16 & 11 & 15 & 9 & 13 \\
\hline Pennsylvania & 35 & 41 & 40 & 49 & 36 & 51 \\
\hline Rhode Island & 0 & 1 & 4 & 4 & 1 & 4 \\
\hline South Carolina & 16 & 13 & 11 & 19 & 10 & 17 \\
\hline South Dakota & 2 & 2 & 3 & 2 & 0 & 1 \\
\hline Tennessee & 19 & 21 & 14 & 13 & 15 & 16 \\
\hline Texas & 57 & 67 & 72 & 47 & 67 & 75 \\
\hline Utah & 4 & 4 & 2 & 5 & 4 & 8 \\
\hline Vermont & 0 & 2 & 0 & 1 & 2 & 1 \\
\hline Virginia & 32 & 21 & 21 & 23 & 31 & 24 \\
\hline Washington & 14 & 21 & 19 & 17 & 24 & 18 \\
\hline West Virginia & 5 & 2 & 5 & 7 & 4 & 0 \\
\hline Wisconsin & 14 & 21 & 24 & 19 & 14 & 12 \\
\hline Wyoming & 1 & 0 & 2 & 2 & 0 & 1 \\
\hline Puerto Rico & 2 & 0 & 0 & 0 & 0 & 0 \\
\hline Respondent does not reside in the United States & 0 & 0 & 0 & 0 & 0 & 2 \\
\hline Total & 874 & 885 & 873 & 870 & 867 & 880 \\
\hline
\end{tabular}

